\title{
Therapeutic Approaches and Advances in Pediatric Stroke
}

\author{
Adam Kirton, MD, MSc, FRCPC, and Gabrielle deVeber MD, MHSc, FRCPC \\ Children's Stroke Program, Department of Pediatrics, Division of Neurology, Faculty of Medicine, University of Toronto, \\ Hospital for Sick Children, M5G 1 X8 Toronto, ON, Canada
}

\begin{abstract}
Summary: Evidence-based therapeutic interventions for pediatric ischemic cerebrovascular disease are beginning to emerge. The primary therapeutic target is usually the pathological prothrombotic disturbance that underlies the majority of pediatric stroke. A battle between anticoagulation and anti-platelet therapies continues to provide controversy and is the inspiration for upcoming randomized trials. Supportive care and neuroprotective strategies are an important consideration in children with stroke. Attempts to determine the safety of acute thrombolytic
\end{abstract}

interventions are also underway. Finally, unique medical and surgical treatments for specific diseases leading to stroke in children continue to evolve. After briefly summarizing the epidemiology, pathophysiology, diagnosis, and outcomes of ischemic strokes in children, treatment approaches and alternatives will be reviewed in detail with emphasis placed on current areas of controversy and future directions for clinical research. Key Words: Cerebrovascular disease, pediatric stroke, child, anticoagulation.

\section{INTRODUCTION AND EPIDEMIOLOGY}

Stroke is a common cause of neurological disease in children and ranks in the top ten causes of death in infants. ${ }^{1,2}$ Studies from the last two decades estimate an incidence of 2-8/100,000 children/year and, in neonates, 1:4000 live births. ${ }^{3,4}$ The current review will focus on ischemic stroke, consisting of arterial ischemic stroke (AIS) and cerebral sinovenous thrombosis (CSVT), emphasizing treatment aspects. For detailed coverage of ischemic and hemorrhagic stroke the reader is referred to recently published reviews. ${ }^{4,5,6}$

AIS comprises infarction in a focal arterial distribution resulting from occlusion of cerebral arteries. CSVT is defined as thrombotic occlusion of cerebral veins or sinuses, and is associated with venous infarction, either bland or hemorrhagic, in about $50 \%$ of cases. In children the proportion of AIS to CSVT is approximately three to one, and in neonates is two to one where the incidence of both is highest. Recurrence rates are highest in older infants and children with AIS where the risk approaches $25-30 \% .^{7}$ The life-long morbidity of stroke in a child

Address all correspondence and reprint requests to: Dr. Gabrielle deVeber, Director - Pediatric Stroke Program, Department of Pediatrics, Division of Neurology, Hospital for Sick Children, 555 University Avenue, Toronto ON M5G 1X8, Phone: 416-813-7722, Fax: 416-8136334, E-mail: gabrielle.deveber@ sickkids.ca lasts decades, amplifying its impact on society and the quality of life of a child and their family.

\section{RISK FACTORS AND PATHOPHYSIOLOGY}

In the newborn period, AIS has distinct associations including acute systemic insults, maternal or obstetrical factors, and prothrombotic states definable in about twothirds of infants. ${ }^{3,6,8}$ In older infants and children, risk factors are identified in 70 to $90 \%$ of children. ${ }^{3,9,10,11}$ About half of children have no prior significant medical history. ${ }^{11}$ While over 100 different risk factors for pediatric stroke have been suggested, ${ }^{7}$ causal relationship to AIS has not necessarily been proven. In pediatric AIS, arteriopathies, cardiac disease, and prothrombotic disorders are the most commonly identified risk factors.

Arteriopathy refers to disorders of cerebral arteries that predispose to stroke and account for over $50 \%$ of AIS in older children. ${ }^{9,11,12}$ Arterial dissection may be related to trauma or can occur spontaneously in both the anterior and posterior circulations. ${ }^{13,14}$ Moyamoya describes the "puff of smoke" appearance on angiography created by collateral vessels that develop secondary to a bilateral, progressive, proximal, non-inflammatory arteriopathy of the distal internal carotid artery. ${ }^{15}$ Moyamoya can be idiopathic or secondary to a long list of both acquired and inherited conditions. Children with sicklecell disease (SCD) stroke due to moyamoya, chronic 
arteriopathy, and acute crises. ${ }^{16}$ Over $20 \%$ of children with SCD will have a stroke and recurrence is common. ${ }^{17}$

Inflammatory arteriopathy can be isolated to cerebral vessels. A monophasic, self-limited form termed transient cerebral arteriopathy of childhood (TCA) is a common cause of AIS in children. ${ }^{11,12,18,19}$ When TCS occurs less than 12 months after chicken pox, it is termed post-varicella angiopathy. ${ }^{11,20,21}$ Isolated angiitis of the CNS (IACNS) affects multiple-sized cerebral vessels without evidence of systemic involvement. ${ }^{22,23,24} \mathrm{~A}$ variety of systemic vasculitides and collagen vascular diseases are also associated with pediatric stroke. ${ }^{24,25}$ Both AIS and CSVT are associated with bacterial meningitis, particularly in neonates and young infants. ${ }^{26}$ Children with HIV can develop a diffuse vasculopathy that may be virus-mediated. ${ }^{27}$ Fibromuscular dysplasia ${ }^{28}$ and postradiation vasculopathy ${ }^{29}$ are rare non-inflammatory vasculopathies. Other vasospastic disorders include migranous and drug-induced infarction. ${ }^{30,31}$

Cardiac diseases are a common predisposing factor for pediatric stroke including congenital malformations, cardiomyopathies, endocarditis, and arrythmias. Diagnostic and interventional catheterization exacerbate the risk. $^{6,11,32,33,34}$ Any potential right-to-left shunt carries a risk of paradoxical thromboembolic stroke. ${ }^{35}$

Prothrombotic disorders, both congenital and acquired, have been associated with $20-50 \%$ of strokes in children. ${ }^{7,8,36}$ Prothrombotic abnormalities of both the mother and fetus have been associated with perinatal AIS. ${ }^{6,37}$ Other hematological disturbances associated with pediatric stroke include iron-deficiency anemia ${ }^{11,38}$ and polycythemia. ${ }^{39}$

In neonates, peripartum factors such as preeclampsia, prolonged rupture of membranes, and placental abnormalities are risks. ${ }^{6,40}$ In older children, metabolic disorders may produce stroke or stroke-like episodes including MELAS, ${ }^{41}$ Fabry disease, ${ }^{42}$ and hyperhomocysteinemia. ${ }^{11}$ Neurocutaneous syndromes associated with pediatric stroke include tuberous sclerosis, neurofibromatosis type 1, epidermal nevus syndromes, incontientia pigmenti, the and the PHACES syndrome. ${ }^{43,44}$ Metabolic derangements of childhood diseases can result in cerebral infarction, including diabetic ketoacidosis ${ }^{45}$ and nephrotic syndrome. ${ }^{46}$

Physiological features including slower blood flow and a greater role of the coagulation system in thrombus formation are particularly important in CSVT pathophysiology. Venous congestion leads to focal cerebral edema progressing to venous infarction and hemorrhage. The superficial sinovenous system is involved twice as often as the deep system, multiple locations affected in nearly $50 \%$, and infarction occurs in over $40 \%$ with two-thirds of these being hemorrhagic. ${ }^{47}$ The most common risk factors for CSVT are dehydration and prothrombotic disorders with others including infection, trauma, cancer/ chemotherapy, and systemic disease. ${ }^{47,48,49}$

\section{DIAGNOSIS AND INVESTIGATIONS}

The diagnosis of AIS and CSVT is suggested by clinical presentations which are age-dependent. Approximately half of perinatal AIS will present acutely, usually as seizures, while focal deficits such as hemiparesis are uncommon. ${ }^{6}$ Most remaining children are diagnosed later in childhood, often within the first year, when hemiparesis or seizures are recognized. ${ }^{8}$ Older children usually present with hemiparesis due to middle cerebral artery territory events. Infarcts are frequently isolated to the basal ganglia, ${ }^{3}$ with resultant movement disorders either at presentation or beginning within several months. ${ }^{50}$ Posterior circulation strokes account for less than $10 \%$ of cases. ${ }^{51}$ Compared with adults, seizures, fever, and headache are more common. ${ }^{52,53}$ Children with CSVT tend to present gradually with diffuse neurological dysfunction, seizures, or symptoms of increased intracranial pressure. ${ }^{47,54}$

History for the neonate with stroke should screen for complications during pregnancy or the perinatal period, the older child for trauma, infection, drug exposure, hematological or cardiac disease, and both for family history. Transient ischemic attacks (TIA) probably occur regularly in children with stroke but have not been well studied. Stroke mimics include migraine, seizures, hypoglycemia, demyelination, and functional disorders. Lengthy delay in diagnosis of stroke in children is common. ${ }^{55}$ Children with suspected stroke should be seen urgently at a tertiary care pediatric care center with access to a multidisciplinary team headed by a pediatric neurologist. All children require measurement of coagulation parameters, blood cell counts, and routine blood work as well as a detailed prothrombotic work-up. ${ }^{56}$ Echocardiography with agitated saline bubble study and cardiology evaluation is required. Imaging of the brain and cerebral vasculature is mandatory. Clinical indications may dictate additional investigations.

Multiple neuroimaging modalities are useful in the diagnosis of pediatric stroke. Computed tomography (CT) can diagnose larger infarcts outside the hyper-acute timeframe and rule-out hemorrhage. MRI, particularly diffusion weighted studies, offer high diagnostic sensitivity and specificity with the concomitant vascular imaging required in all children. ${ }^{6,57} \mathrm{MR}$ angiography (MRA) can detect most large vessel vasculopathies in children. ${ }^{58,59}$ Advanced neuroimaging technology is providing unique avenues to explore the mechanisms of stroke in children and the response of the developing brain to injury. Cranial ultrasonography has limited sensitivity in detecting perinatal strokes. ${ }^{60}$ Transcranial Doppler ultrasound (TCD) can predict the risk of stroke 
and guide therapy in children with SCD ${ }^{61}$ Cerebral angiography remains the gold standard for neurovascular imaging in children, and may be required for certain


CSVT is challenging and is reviewed elsewhere. ${ }^{62} \mathrm{CT}$ venography (CTV) provides a quick and accurate diagnosis of CSVT but contrast MR venography (MRV) offers comparable accuracy and provides assessment of brain parenchyma while avoiding radiation. ${ }^{63}$

\section{OUTCOME}

Outcomes from pediatric stroke are well defined but accurate early predictors remain elusive. Many children with hemiplegic cerebral palsy $(\mathrm{CP})$ and a smaller proportion with bilateral $\mathrm{CP}$ have had a perinatal stroke. ${ }^{6,64}$ In symptomatic perinatal stroke, mortality rates are 10fold higher compared to older children ${ }^{1}$ and neurological deficits or epilepsy occur in 50-66\% of survivors. ${ }^{3,40,65,66}$ Deficits include sensori-motor, language, visual, cognitive and behavioural problems. ${ }^{3,40,65,66}$. The outcome from stroke in infancy is often assumed to be better than that for older children, which is in turn better than adults, ${ }^{6,65}$ a finding often attributed to increased "plasticity" though proof of this and an understanding of the mechanisms that might underlie it are lacking.

More than half of childhood AIS survivors will live with moderate to severe disabilities ${ }^{67,53,68}$ and case fatality rates range from 5\% to $28 \% .{ }^{53,67}$ Motor deficits are most frequent, followed by communication disorders and neuropsychiatric, cognitive, and behavioural complications. ${ }^{67,68,69,70,71}$ Epilepsy complicates at least $15 \%$ of childhood stroke, ${ }^{72,67}$ hyperkinetic movement disorders may be disabling, ${ }^{73,74}$ and headache disorders occur in one-third of cases. ${ }^{67}$ Compared with AIS, outcome is generally better after CSVT. In the largest prospective study, $65 \%$ of 160 infants and children with CSVT were normal though the mortality rate approached $10 \% .{ }^{47}$ The remaining third had significant neurological deficits that often worsened over time and $20 \%$ of survivors had epilepsy. Other studies have reported comparable outcomes. ${ }^{54,67,75}$ Decrease in quality of life is present in over half of stroke survivors, affects the entire family, ${ }^{76}$ and relates to both neurological deficits and psychosocial factors. ${ }^{77}$

\section{TREATMENT AND PREVENTION}

While the evidence for most treatment approaches in pediatric stroke is desperately short, some consensus regarding therapeutic strategies is emerging from multicenter collaborations with areas of divergent opinion providing opportunities for randomized controlled clinical trials (RCCT). With the exception of SCD, best available evidence is based on theory, extrapolation from adult studies, and case-control or cohort studies in children. Completion of the most pressing RCCT's is a top priority in childhood stroke research and international collaborations have been established and are currently facilitating their initiation. Two separate, evidence-based treatment guidelines have recently been published and are referred to here as the Chest ${ }^{78}$ and UK guidelines ${ }^{79}$ respectively. Both were created by panels that included pediatric neurologists and hematologists from multiple centers. While attempting to be evidence-based, most recommendations receive the lowest affirmative grade of support due to the lack of RCCT. Both publications acknowledge these limitations and stress that treatment must always be tailored to individual patients in accordance with best clinical practice. These guidelines have been compared and contrasted in detail elsewhere. ${ }^{80}$ The following review of pediatric stroke treatment follows a chronological approach from hyperacute (hours) to acute (days), subacute (weeks to months), and chronic (years) interventions.

\section{Hyperacute Treatment: Thrombolysis}

Intravenous and intra-arterial thrombolysis, now routine in adult stroke, remains anecdotal in children. ${ }^{81,82,83,84,85}$ In adults the absolute risk reduction for poor outcome is approximately $15 \%$ with thrombolysis, with a number needed to treat of 7-8 in the largest RCCT. ${ }^{86}$ Careful patient selection and adherence to protocol are critical to optimize the risk:benefit balance of thrombolytic therapy in adults ${ }^{87,88}$ but no studies in pediatric stroke have been completed..

Numerous barriers must be overcome before hyperacute therapies can be applied to children. Foremost is determining if differences in stroke mechanisms, and vascular and coagulation systems confer advantages or risks for thrombolysis. Limited access to timely treatment is highlighted by a study from an experienced stroke center where fewer than $25 \%$ of pediatric cases were diagnosed within the 3-6 hour time window. ${ }^{55} \mathrm{Im}$ proved education of primary care physicians and the public are required to overcome this delay to diagnosis. The broad differential diagnosis for acute neurological deficits in children requires rapid but definitive neuroimaging protocols to confirm infarction and arterial occlusion. Finally, measures of acute stroke severity to identify patients at risk of poor outcome are required and a pediatric modification of the NIH stroke scale, the PedNIHSS, is currently in development.

Hemorrhage is the primary concern with thromoboytic use though recent evidence suggests that younger age and careful patient selection minimize the risk in adults. ${ }^{88}$ Tissue plasminogen activator (tPA) administered to children for non-cerebral thrombosis has shown good success in clot lysis but major bleeding in $11 \%$ and intracranial hemorrhage in 1-2\%. ${ }^{89}$ Alternative acute in- 
terventions including mechanical clot manipulation and cerebral angioplasty have only been described in isolated pediatric cases. ${ }^{84,90}$ In the case of severe CSVT, the role of catheter-introduced administration of thrombolytics agents remains controversial and could be considered a last resort for children with severe, progressive disease who are failing systemic anticoagulation.

Due to the theoretical risks and lack of evidence, neither the UK nor Chest guideline recommends the use of thrombolytics in pediatric stroke. ${ }^{78,79}$ However, there is reason to believe that the non-standardized use of thrombolytics in children occurs regularly. Therefore, a safety and feasibility pilot study for the use of intravenous or intrarterial tPA in children six years or older presenting early with severe AIS and proven arterial occlusion has recently been initiated at several North American centers.

\section{Acute and Subacute Treatment: Anti-platelet versus anti-coagulation}

Therapies directed at the inhibition of either platelet or coagulation cascade function play a role in the acute, subacute, and chronic phases of pediatric stroke treatment. Substantial differences exist between adult and pediatric platelet, coagulation and vascular systems ${ }^{91}$ and, hence, stroke pathophysiology and approaches to treatment. A disturbance of the coagulation system is supported in CSVT and AIS secondary to arterial dissection, cardiogenic thromboembolism, prothrombotic states, paradoxical embolism, or severe (slow flow) arterial stenosis. Most other vasculopathies and many idiopathic strokes more likely involve platelet-mediated mechanisms. Population-based studies suggest more than half of children with AIS will receive at least one of aspirin (ASA), unfractionated heparin (UFH), low molecular weight heparin (LMWH), or warfarin although the indications appear to range widely and issues of dosing and duration are unresolved. ${ }^{3}$ Good evidence supports the safety of all of these agents in children with stroke. ${ }^{3,92,93,94}$

Anticoagulation therapy (ACT) is not supported by evidence for the early treatment of most arterial strokes in adults. However, differences in the pathophysiology of the most common causes of pediatric AIS underlie support for the use of early ACT. A decision to treat must balance estimated benefit of preventing further strokes or thrombus propagation against risk of hemorrhage. Contraindications to ACT include significant hemorrhagic transformation, uncontrolled hypertension, or known bleeding disorder. ${ }^{78}$ Options for acute ACT generally include heparin or LMWH while continuation of LMWH or oral ACT with coumadin are the alternatives for the subacute timeframe. The advice of a thrombosis expert is invaluable in the management of anticoagulated pediatric stroke patients.
Heparin inhibits the coagulation cascade at multiple sites but most prominently by inactivating thrombin via activation of antithrombin. ${ }^{95}$ Age-dependent differences in both thrombin and antithrombin levels complicate heparin ACT in young children, particularly neonates. ${ }^{96}$ Maintenance dosing recommendations are as follows: infants under 12 months ( 28 units $/ \mathrm{kg} / \mathrm{hr}$ ), older children (20 units/ $/ \mathrm{kg} / \mathrm{hr}$ ), and adolescents (18 units/kg/hr). ${ }^{78} \mathrm{An}$ initial bolus is usually not given to reduce a theoretical risk of increased hemorrhage. APTT are monitored for dosing adjustments with a target of 60-85 seconds though heparin levels may also be employed. ${ }^{96}$ Early complications of heparin include hemorrhage and heparin-induced thrombocytopenia which occurs in less than $4 \%$ of cases. ${ }^{97}$

Low molecular weight heparins (LMWH) are smaller molecular subcomponents of UFH and are emerging as the preferred agent for subacute, and possibly acute, ACT in children with stroke. Advantages of LMWH include subcutaneous administration, reproducible pharmacokinetics, and a better safety profile with a low rate of hemorrhage. ${ }^{92,94,98}$ Monitoring is easier with less frequent measurement of anti-factor Xa levels. Drawbacks include less predictable anticoagulation compared to adults and relative lack of reversibility. ${ }^{78}$ Several varieties of LMWH and dosing schedules are described elsewhere. ${ }^{78}$ Enoxaparin is the most commonly used variety and typical treatment dosing is $1.5 \mathrm{mg} / \mathrm{kg}$ daily in infants under 2 months and $1.0 \mathrm{mg} / \mathrm{kg}$ daily in older children. ${ }^{78}$

The clearest discrepancy between the UK and Chest guidelines is the initial choice of acute therapy for AIS. The Chest supplement supports early initiation of ACT with either LMWH or UFH for the first 5-7 days and until a cardiac source or dissection has been excluded. ${ }^{78}$ Children are usually then changed to ASA (3-5 mg/kg/d) or, in cases due to cardiogenic embolism or dissection, remain on ACT (coumadin or LMWH) for at least 3 months. In contrast, the UK guideline recommends the initiation of ASA at $5 \mathrm{mg} / \mathrm{kg} /$ day except in patients with contraindications of intracranial hemorrhage or SCD. ${ }^{79}$ Early ACT is supported only in cases of proven arterial dissection and is considered in suspected cardiac thromboembolism. Early treatment of neonatal AIS treatment is even less studied and was not addressed by the UK guidelines. The use of ACT with UFH or LMWH for 3 months in neonates with definitive cardioembolic source is supported by the Chest guideline. ${ }^{78}$ The only other well supported acute intervention is the use of exchange transfusions to lower hemoglobin S concentrations to less than $30 \%$ in children with SCD and stroke. ${ }^{79}$

Several important differences in CSVT pathophysiology dictate differences in early treatment. Venous thrombosis is often gradual and progressive, evolving from venous congestion to infarction with possible hemorrhage. Slow flow heightens the role of the coagulation 
system and allows thrombus progression over time. Closer parallels likely exist between adult and pediatric CSVT where risk factors and pathophysiology are similar. Consistent evidence supports ACT with heparin in adult CSVT for preventing death and improving neurological outcome, even among patients with initial evidence of bleeding. ${ }^{99,100,101}$ Good safety profiles for LMWH, UFH, and warfarin have been documented in both neonates and children with non-hemorrhagic CSVT. ${ }^{47,93,102}$

The Chest guidelines recommend ACT in children with CSVT and in neonates without major hemorrhage. ${ }^{78}$ Initial therapy with either heparin or LMWH is continued for 5-7 days then changed to LMWH for ongoing therapy. For neonates, the duration is usually 6-12 weeks while in older children, checkpoints are set at 3 and 6 months. Repeat venous imaging is performed at the earlier time point and ACT is discontinued if full recanalization has occurred or is continued to the second time point if it has not. Oral ACT with coumadin is an alternative for older children though a comparison to LMWH has not been performed. In the case of large initial hemorrhage that prevents initiation of ACT, repeat imaging at 5-7 days is indicated to determine if thrombus propagation has occurred in which case ACT should then be considered. In the case of continued clot progression on maximal ACT, systemic or regional thrombolytic therapy can be considered though this is not well studied in adults ${ }^{103}$ and has only been reported anecdotally in children. ${ }^{104,105}$ Additional early treatments for pediatric CSVT include supportive measures (see below) as well as antibiotic therapy for septic thrombophlebitis, and management of increased intracranial pressure or hydrocephalus. Current issues to be resolved in the treatment of pediatric CSVT include the risk of treating large hemorrhagic infarcts, the ideal duration of therapy, neuroimaging endpoints to guide therapy, and a comparison of heparin versus $\mathrm{LMWH}^{80}$

\section{Acute Treatment: Supportive Care and Prevention of Secondary Brain Injury}

Early supportive care is essential to prevent secondary brain injury in children with stroke. ${ }^{106}$ Based primarily on adult evidence, ${ }^{107}$ this includes normalization of blood sugar, temperature, ventilation/oxygenation, blood volume and blood pressure. Both hyper- and hypoglycemia are associated with poor outcome and larger infarcts. ${ }^{108,109}$ The theoretically protective effect of hypothermia (reviewed in this volume) has not been proven in focal ischemic brain injury in children though hyperthermia likely exacerbates injury ${ }^{110}$ and infection should be aggressively treated. Seizures may worsen ischemic brain injury ${ }^{111}$ and should be treated promptly. Improved understanding of the cellular and molecular processes that mediate ischemic brain injury has lead to numerous trials of potential neuroprotective therapies in stroke ${ }^{112}$ though results have been disappointing. Neuroprotective therapies face additional challenges in pediatric stroke where manipulations of cellular biology may have unwanted effects on brain development. ${ }^{64}$

Malignant cerebral edema is a significant complication of large strokes, and a greater ratio of brain tissue to intracranial volume exacerbates the problem in children. Intracranial pressure monitoring, mannitol or hypertonic saline may be unsuccessful, and evidence supporting emergency decompressive craniectomy is emerging. ${ }^{113}$ The procedure may be life-saving if done early in cases of impending herniation, is associated with good outcomes in young stroke patients, ${ }^{114}$ and is supported by published guidelines. ${ }^{79}$ Anticipated surgical intervention for malignant cerebral edema might also influence the acute treatment choice towards the more easily reversible UFH rather than LMWH or ASA. Additional supportive treatment issues including prevention of aspiration, nutrition, skin care, and DVT prophylaxis should be considered. Care in a tertiary pediatric center with access to relevant specialists and investigations should be considered the standard ${ }^{79}$ as specialized stroke care has been shown to improve outcomes in adults.

\section{Chronic Treatment: Secondary Stroke Prevention}

Recurrence rates for pediatric AIS range from 10-25\% in treated, and as high as $50 \%$ in untreated children outside the neonatal period. ${ }^{9,10,115,116}$ Recurrence risk is maximal in the first six months, and is increased in the presence of vasculopathy or multiple risk factors. ${ }^{9,10,56}$ Certain prothrombotic disorders ${ }^{56}$ carry an increased recurrence risk while others do not. ${ }^{117}$ In perinatal AIS recurrence rates are less than 5\%. ${ }^{67,118}$ The first RCCTs of secondary prevention in pediatric AIS are now in development. Primary prevention opportunities include children undergoing cardiac surgery and mothers at increased risk for fetal stroke.

Anti-platelet treatment, usually with aspirin (ASA), is the current mainstay for long-term prevention of recurrent AIS in children. Adult studies indicate that low dose ASA treatment provides a $25 \%$ risk reduction ${ }^{119,120}$ and is equivalent to vitamin $\mathrm{K}$ antagonists for stroke prevention outside of atrial fibrillation. ${ }^{121}$ A prospective, nonrandomized study of children with AIS on either ASA or LMWH demonstrated a failure rate of approximately $10 \%$ in children selected by clinicians for each therapy. ${ }^{94}$ Both the UK and Chest guidelines support the use of ASA for secondary stroke prevention in most cases of childhood AIS with recommended doses ranging from $1-5 \mathrm{mg} / \mathrm{kg} /$ day $^{78,79}$ which appear safe in children. ${ }^{94,122}$ Side effects of ASA are minimal at low doses and include gastric upset and easy bruisability. Significant hemorrhage is rare and Reye syndrome is not reported 
with low dose ASA, however reduction of dosage during febrile illness or influenza vaccination is recommended.

For children with non-vasculopathy strokes, the guidelines disagree on the use of long-term $\mathrm{ASA}^{78,79}$ and such areas of clear equipoise will likely serve as starting points for upcoming RCCT. ${ }^{80}$ Measurement of ASA efficacy via platelet functional assays may help predict the success or failure of preventative therapy. ${ }^{123}$ Preliminary evidence for the safety and indications of other antiplatelet agents such as clopidogrel in pediatric stroke is emerging. ${ }^{124}$ In the situation of recurrent stroke in a patient already on anti-platelet therapy, the UK guideline suggests consideration of $\mathrm{ACT}^{79}$ while this issue was not addressed in the Chest publication.

ACT is considered for long-term prevention in children with AIS with high risk heart disease or severe prothrombotic disorders. Supporting evidence comes from the Warfarin-Aspirin Recurrent Stroke Study(WARRS) ${ }^{121}$ where a subgroup analysis of "cryptogenic" strokes (not due to atherosclerosis, atrial fibrillation, or lacunar infarction), a group more similar to pediatric AIS patients, demonstrated a significant benefit of ACT over ASA in secondary stroke prevention. Warfarin is a vitamin $\mathrm{K}$ antagonist that inhibits production of multiple components of the coagulation cascade. Approximately 72 hours of oral warfarin is required for effect and a target INR of 2-3 is appropriate for most children. The initial dose is $0.2 \mathrm{mg} / \mathrm{kg}$ with subsequent dosing adjustments based on published nomograms. ${ }^{78}$ Advantages of effective anticoagulation and oral administration are offset by complications of regular monitoring and risks of drug interactions. Special consideration regarding vitamin $\mathrm{K}$ levels are required in breastfed infants, children with gastrointestinal disease, and those on total parenteral nutrition. The theoretical increased risk of hemorrhage related to higher physical activity in children is probably small though this has not been studied and recommendations against high-risk activities such as contact sports are suggested.

Education and family support are important. ${ }^{79}$ Attention to psychosocial complications and development of educational and supportive resources are important areas of progress in pediatric stroke care. The use of alternative therapies, including several with potential to influence coagulation, is common in children with stroke from certain cultural groups and should be inquired about. ${ }^{125}$

\section{Disease-Specific Therapies}

In the only RCCT in pediatric stroke to date, the STOP trial demonstrated a $92 \%$ risk reduction for SCD children receiving regular blood transfusions. ${ }^{61}$ All SCD children with clinical or neuroimaging evidence of cerebral ischemia or those who demonstrate intracranial stenosis on TCD (velocities $>200 \mathrm{~cm} / \mathrm{sec}$ ) should receive blood transfusions every 3-6 weeks to maintain hemoglobin $\mathrm{S}$ levels below 30\%. ${ }^{78,79}$ Annual screening for cerebral vasculopathy with TCD is recommended from age three years but optimal duration of therapy and whether asymptomatic children with normal velocities would benefit from transfusions is unknown. Anti-platelet or anticoagulant therapies in SCD remain to be assessed. ${ }^{126}$ Hydroxyurea therapy may also prevent stroke in SCD. ${ }^{127}$ Nocturnal oxygen saturation inversely correlated with risk of cerebral ischemic events and nocturnal oxygen supplementation may be an additional opportunity for intervention. $^{128}$

Treatment of moya moya disease (MMD) presents unique challenges and controversies. There are no proven medical therapies though a theoretical acid-base sensitive vaso-reactive mechanism that may underlie AIS in children with moya moya ${ }^{129}$ has lead some to treat with carbonic anhydrase inhibitors. Patients are often treated with long-term ASA though this is unproven and must be balanced against a shifting risk toward hemorrhagic stroke with advancing age in MMD. A wide variety of surgical therapies have been employed though supporting evidence is only just emerging. In direct procedures, extracranial blood vessels such as the superficial temporal artery, are anastomosed to distal portions of intracranial vessels, usually the middle cerebral artery (MCA). Indirect procedures introduce new vascular supply to tenuously perfused brain by relocating extra-cranial arteries or vascularized tissues such as muscle to the overlying meningeal surface. Combined direct and indirect procedures may maximize cerebral collateralization. ${ }^{130}$ Recent evidence suggests that younger age of onset may carry a higher risk of recurrent stroke and worse outcome and promotes early surgery. ${ }^{131}$ Surgeryrelated infarctions occur in approximately $5-10 \%$ of cases. ${ }^{130,131}$

Other disease specific therapies include immunosuppression with steroids, cyclophosphamide, or other agents for progressive cerebral vasculitis. ${ }^{24} \mathrm{~A}$ role for acyclovir in post-varicella angiopathy remains theoretical. Stroke secondary to inborn metabolic errors may be treatable with enzyme replacement in Fabry disease, vitamin therapy in homocystinuria, and "cocktail therapy" for MELAS.

Preventative care includes attention to modifiable risk factors to reduce future stroke risk. Recommendations include regular exercise, a balanced diet, and avoidance of smoking. Children with stroke and a prothrombotic disorder should be counseled to avoid episodic dehydration and prophylactic dosing of anticoagulation in highrisk situations has been suggested. Oral contraceptives and vasoconstrictor agents such as triptans, ergots, or sympathomimetics should be avoided.

Early, aggressive multimodal rehabilitation therapy including physical, occupational, and speech modalities is essential in the treatment of all children with stroke. ${ }^{79}$ 
The constant evolution of the developing brain complicates the formal evaluation of rehabilitation strategies in pediatric stroke patients. Most rehabilitation studies have focused on motor function as it is the most common deficit and the most amenable to evaluation. An RCT has demonstrated the effectiveness of constraint-induced therapy in children with congenital hemiplegia. ${ }^{132}$ Other strategies including inhibitive casting, lycra splinting, treadmill training, and functional electrical stimulation remain to be studied in pediatric stroke. The UK guidelines recommend muscle strengthening to improve function and minimize contractures, Botox injections for spasticity, and ankle-foot orthoses for gait and contracture prevention. ${ }^{79}$

Formal neuropsychological evaluation is required to document cognitive and behavioural deficits and determine educational resource and environment needs. Serial assessments may be required as development proceeds or in children with recurrent events. Language difficulties are common and speech-language therapy may be required. Tailoring of interventions to an individual child's lifestyle, goals, and level of functioning should be integrated with school and home environments. ${ }^{79}$

\section{Summary}

An evolution in the approaches to treatment of pediatric stroke has paralleled other recent advances in clinical research. A multitude of current interventions are likely improving outcomes but definitive evidence is still lacking in most circumstances. Established international collaborations will provide the power required to conduct the most pressing clinical trials in the near future and begin to clarify the best therapies for children with stroke.

Acknowledgments: Dr. Kirton is a Clinical Research Fellow of the American Academy of Neurology Foundation and Alberta Heritage Foundation for Medical Research

\section{REFERENCES}

1. Murphy SL. Deaths: final data for 1998. Natl Vital Stat Rep 48:1-105, 2000.

2. Fullerton HJ, Chetkovich DM, Wu YW, Smith WS, Johnston SC. Deaths from stroke in US children, 1979 to 1998. Neurology 59:34-39, 2002.

3. deVeber G, Canadian Paediatric Ischemic Stroke Study Group. Canadian Paediatric Ischemic Stroke Registry: Analysis of children with arterial ischemic stroke. Ann Neurol 48:514, 2000.

4. Lynch JK, Hirtz DG, deVeber G, Nelson KB. Report of the National Institute of Neurological Disorders and Stroke workshop on perinatal and childhood stroke. Pediatrics 109:116-123, 2002.

5. deVeber G. Stroke and the child's brain: an overview of epidemiology, syndromes and risk factors. Curr Opin Neurol 15:133138,2002

6. Nelson KB, Lynch JK. Stroke in newborn infants. Lancet Neurol $3: 150-158,2004$.

7. Lynch JK. Cerebrovascular disorders in children. Curr Neurol Neurosci Rep 4:129-138, 2004.

8. Golomb MR, MacGregor DL, Domi T, Armstrong DC, McCrindle BW, Mayank S et al. Presumed pre- or perinatal arterial ischemic stroke: risk factors and outcomes. Ann Neurol 50:163-168, 2001.

9. Chabrier S, Husson B, Lasjaunias P, Landrieu P, Tardieu M. Stroke in childhood: outcome and recurrence risk by mechanism in 59 patients. J Child Neurol 15:290-294, 2000.

10. Lanthier S, Carmant L, David M, Larbrisseau A, de Veber G. Stroke in children: the coexistence of multiple risk factors predicts poor outcome. Neurology 54:371-378, 2000.

11. Ganesan V, Prengler M, McShane MA, Wade AM, Kirkham FJ Investigation of risk factors in children with arterial ischemic stroke. Ann Neurol 53:167-173, 2003.

12. Sebire G, Fullerton H, Riou E, deVeber G. Toward the definition of cerebral arteriopathies of childhood. Curr Opin Pediatr 16: 617-622, 2004.

13. Fullerton HJ, Johnston SC, Smith WS. Arterial dissection and stroke in children. Neurology 57:1155-1160, 2001

14. Chabrier S, Lasjaunias P, Husson B, Landrieu P, Tardieu M. Ischaemic stroke from dissection of the craniocervical arteries in childhood: report of 12 patients. Eur J Paediatr Neurol 7:39-42, 2003.

15. Ishii K, Isono M, Kobayashi H, Kamida T. Temporal profile of angiographical stages of moyamoya disease: when does moyamoya disease progress? Neurol Res 25:405-410, 2003.

16. Steen RG, Xiong X, Langston JW, Helton KJ. Brain injury in children with sickle cell disease: prevalence and etiology. Ann Neurol 54:564-572, 2003.

17. Pegelow CH, Macklin EA, Moser FG, Wang WC, Bello JA, Miller ST et al. Longitudinal changes in brain magnetic resonance imaging findings in children with sickle cell disease. Blood 99: 3014-3018, 2002.

18. Shirane R, Sato S, Yoshimoto T. Angiographic findings of ischemic stroke in children. Childs Nervous System 8:432-436, 1992.

19. Chabrier S, Rodesch G, Lasjaunias P, Tardieu M, Landrieu P, Sebire G. Transient cerebral arteriopathy: a disorder recognized by serial angiograms in children with stroke. J Child Neurol 13:27-32, 1998.

20. Sebire G, Meyer L, Chabrier S. Varicella as a risk factor for cerebral infarction in childhood: a case- control study. Ann Neurol 45:679-680, 1999.

21. Askalan R, Laughlin S, Mayank S, Chan A, MacGregor D, Andrew $\mathrm{M}$ et al. Chickenpox and stroke in childhood: a study of frequency and causation. Stroke 32:1257-1262, 2001.

22. Lanthier S, Lortie A, Michaud J, Laxer R, Jay V, deVeber G. Isolated angiitis of the CNS in children. Neurology 56:837-842, 2001.

23. Gallagher KT, Shaham B, Reiff A, Tournay A, Villablanca JP, Curran J et al. Primary angiitis of the central nervous system in children: 5 cases. J Rheumatol 28:616-623, 2001.

24. Benseler S, Schneider R. Central nervous system vasculitis in children. Curr Opin Rheumatol 16:43-50, 2004.

25. Graf WK, Milstein JM, Sherry DD. Stroke and mixed connective tissue disease. J Child Neurol 8:256-259, 1993.

26. Takeoka M, Takahashi T. Infectious and inflammatory disorders of the circulatory system and stroke in childhood. Curr Opin Neurol 15:159-164, 2002.

27. Patsalides AD, Wood LV, Atac GK, Sandifer E, Butman JA, Patronas NJ. Cerebrovascular disease in HIV-infected pediatric patients: neuroimaging findings. AJR Am J Roentgenol 179:9991003, 2002.

28. Camacho A, Villarejo A, Moreno T, Simon R, Munoz A, Mateos F. Vertebral artery fibromuscular dysplasia: an unusual cause of stroke in a 3-year-old child. Dev Med Child Neurol 45:709-711, 2003.

29. Omura M, Aida N, Sekido K, Kakehi M, Matsubara S. Large intracranial vessel occlusive vasculopathy after radiation therapy in children: clinical features and usefulness of magnetic resonance imaging. Int J Radiat Oncol Biol Phys 38:241-249, 1997.

30. Nezu A, Kimura S, Ohtsuki N, Tanaka M, Takebayashi S. Acute confusional migraine and migrainous infarction in childhood. Brain Dev 19:148-151, 1997.

31. Santiago R, Dominguez M, Campos CJ. [Cerebral infarct in childhood as a complication of migraine with aura. A case report]. Rev Neurol 33:1143-1148, 2001. 
32. Menache CC, du Plessis AJ, Wessel DL, Jonas RA, Newburger JW. Current incidence of acute neurologic complications after open-heart operations in children. Ann Thorac Surg 73:1752$1758,2002$.

33. Domi T, Edgell D, McCrindle B.W, William G.W, MacGregor D, Kaplan D et al. Frequency and predictors of vasoocclusive strokes associated with congenital heart disease. Ann Neurol 52:S129133, 2002.

34. Monagle P, Karl TR. Thromboembolic problems after the Fontan operation. Semin Thorac Cardiovasc Surg Pediatr Card Surg Апnи 5:36-47, 2002.

35. Mas JL, Arquizan C, Lamy C, Zuber M, Cabanes L, Derumeaux $\mathrm{G}$ et al. Recurrent cerebrovascular events associated with patent foramen ovale, atrial septal aneurysm, or both. $N$ Engl J Med 345:1740-1746, 2001.

36. Barnes $\mathrm{C}$, deVeber G. Prothrombotic abnormalities in childhood ischaemic stroke. Submitted to Thrombosis Research 2004.

37. Nowak-Goettl U, von Eckardstein A, Junder R, Schuierer G, Strater R. Lipoprotein (a) and genetic polymorphisms of MTHFR TT677, factor V G1691A, and prothrombin G20210A are risk factors of spontaneous ischaemic stroke in childhood. Thromb Haemostas suppl: 1999.

38. Hartfield DS, Lowry NJ, Keene DL, Yager JY. Iron deficiency: a cause of stroke in infants and children. Pediatr Neurol 16:50-53, 1997.

39. Gunther G, Junker R, Strater R, Schobess R, Kurnik K, Kosch A et al. Symptomatic ischemic stroke in full-term neonates:role of acquired and genetic prothrombotic risk factors. Stroke 31:24372441, 2000.

40. Lee J, Croen LA, Lindan C, Nash KB, Yoshida CK, Ferriero DM et al. Predictors of outcome in perinatal arterial stroke: A population-based study. Ann Neurol 58:303-308, 2005.

41. Iizuka T, Sakai F, Suzuki N, Hata T, Tsukahara S, Fukuda M et al. Neuronal hyperexcitability in stroke-like episodes of MELAS syndrome. Neurology 59:816-824, 2002.

42. Desnick RJ, Brady RO. Fabry disease in childhood. J Pediatr 144:S20-S26, 2004.

43. Guillamo JS, Creange A, Kalifa C, Grill J, Rodriguez D, Doz F et al. Prognostic factors of CNS tumours in Neurofibromatosis 1 (NF1): a retrospective study of 104 patients. Brain 126:152-160, 2003.

44. Bhattacharya JJ, Luo CB, Alvarez H, Rodesch G, Pongpech S, Lasjaunias PL. PHACES syndrome: a review of eight previously unreported cases with late arterial occlusions. Neuroradiology 46:227-233, 2004.

45. Ho J, Pacaud D, Hill MD, Ross C, Hamiwka L, Mah JK. Diabetic ketoacidosis and pediatric stroke. CMAJ 172:327-328, 2005.

46. Igarashi M, Roy S, III, Stapleton FB. Cerebrovascular complications in children with nephrotic syndrome. Pediatr Neurol 4:362365, 1988.

47. deVeber G, Andrew M, Canadian Pediatric Ischemic Stroke Study Group. Cerebral sinovenous thrombosis in children. N Engl J Med 345:417-423, 2001.

48. Heller C, Heinecke A, Junker R, Knofler R, Kosch A, Kurnik K et al. Cerebral venous thrombosis in children: a multifactorial origin. Circulation 108:1362-1367, 2003.

49. Sebire G, Tabarki B, Saunders DE, Leroy I, Liesner R, SaintMartin $\mathrm{C}$ et al. Cerebral venous sinus thrombosis in children: risk factors, presentation, diagnosis and outcome. Brain 128:477489, 2005

50. Demierre B, Rondot P. Dystonia caused by putamino-capsulocaudate vascular lesions. J Neurol Neurosurg Psychiatry 46:404409, 1983.

51. Ganesan V, Chong WK, Cox TC, Chawda SJ, Prengler M, Kirkham FJ. Posterior circulation stroke in childhood: risk factors and recurrence. Neurology 59:1552-1556, 2002.

52. Trescher WH. Ischemic stroke syndromes in childhood. Pediatr Ann 21:374-383, 1992.

53. Delsing BJ, Catsman-Berrevoets CE, Appel IM. Early prognostic indicators of outcome in ischemic childhood stroke. Pediatr Neurol 24:283-289, 2001.

54. Carvalho KS, Bodensteiner JB, Connolly PJ, Garg BP. Cerebral venous thrombosis in children. J Child Neurol 16:574-580, 2001.
55. Gabis LV, Yangala R, Lenn NJ. Time lag to diagnosis of stroke in children. Pediatrics 110:924-928, 2002.

56. Strater R, Becker S, von Eckardstein A, Heinecke A, Gutsche S, Junker R et al. Prospective assessment of risk factors for recurrent stroke during childhood-a 5-year follow-up study. Lancet 360: 1540-1545, 2002.

57. Hunter JV. New radiographic techniques to evaluate cerebrovascular disorders in children. Semin Pediatr Neurol 7:261-277, 2000.

58. Ganesan V, Savvy L, Chong WK, Kirkham FJ. Conventional cerebral angiography in children with ischemic stroke. Pediatr Neurol 20:38-42, 1999.

59. Husson B, Lasjaunias P. Radiological approach to disorders of arterial brain vessels associated with childhood arterial stroke-a comparison between MRA and contrast angiography. Pediatr Radiol 34:10-15, 2004.

60. Golomb MR, Dick PT, MacGregor DL, Armstrong DC, deVeber GA. Cranial ultrasonography has a low sensitivity for detecting arterial ischemic stroke in term neonates. J Child Neurol 18:98103, 2003.

61. Adams RJ, McKie VC, Hsu L, Files B, Vichinsky E, Pegelow C et al. Prevention of a first stroke by transfusions in children with sickle cell anemia and abnormal results on transcranial Doppler ultrasonography. N Engl J Med 339:5-11, 1998.

62. Shroff M, deVeber G. Sinovenous thrombosis in children. Neuroimaging Clin N Am 13:115-138, 2003.

63. Farb RI, Scott JN, Willinsky RA, Montanera WJ, Wright GA, terBrugge KG. Intracranial venous system: gadolinium-enhanced three-dimensional MR venography with auto-triggered elliptic centric-ordered sequence-initial experience. Radiology 226:203209, 2003.

64. Ferriero DM. Neonatal brain injury. N Engl J Med 351:19851995, 2004.

65. Lynch J, Hirtz D, deVeber G, Nelson K. Report of the national institute of neurological disorders and stroke workshop on perinatal and childhood stroke. Pediatr (submitted) 2001.

66. deVeber G, MacGregor D, Curtis R, Friefeld S, Anderson P, Chan A et al. Neurological Outcome in Survivors of Neonatal Arterial Ischemic Stroke. Pediatr Res 53:537A, 2003.

67. deVeber G, MacGregor D, Curtis R, Mayank S. Neurologic outcome in survivors of childhood arterial ischemic stroke and sinovenous thrombosis. J Child Neurol 15:316-324, 2000.

68. Ganesan V, Hogan A, Shack N, Gordon A, Isaacs E, Kirkham FJ. Outcome after ischaemic stroke in childhood. Dev Med Child Neurol 42:455-461, 2000.

69. Hurvitz EA, Beale L, Ried S, Nelson VS. Functional outcome of paediatric stroke survivors. Pediatr Rehabil 3:43-51, 1999.

70. Max JE, Mathews K, Lansing AE, Robertson BA, Fox PT, Lancaster JL et al. Psychiatric disorders after childhood stroke. J Am Acad Child Adolesc Psychiatry 41:555-562, 2002.

71. Lansing AE, Max JE, Delis DC, Fox PT, Lancaster J, Manes FF et al. Verbal learning and memory after childhood stroke. J Int Neuropsychol Soc 10:742-752, 2004.

72. Yang JS, Yong DP, Hartlage P. Seizures associated with stroke in childhood. Pediatr Neurol 12:136-138, 1995.

73. Kwak CH, Jankovic J. Tourettism and dystonia after subcortical stroke. Mov Disord 17:821-825, 2002.

74. Boardman JP, Ganesan V, Rutherford MA, Saunders DE, Mercuri E, Cowan F. Magnetic resonance image correlates of hemiparesis after neonatal and childhood middle cerebral artery stroke. Pediatrics 115:321-326, 2005.

75. De Schryver EL, Blom I, Braun KP, Kappelle LJ, Rinkel GJ, Peters AC et al. Long-term prognosis of cerebral venous sinus thrombosis in childhood. Dev Med Child Neurol 46:514-519, 2004.

76. Gordon AL, Ganesan V, Towell A, Kirkham FJ. Functional outcome following stroke in children. J Child Neurol 17:429-434, 2002.

77. Friefeld S, Yeboah O, Jones JE, deVeber G. Health-related quality of life and its relationship to neurological outcome in child survivors of stroke. CNS Spectr 9:465-475, 2004.

78. Monagle P, Chan A, Massicotte P, Chalmers E, Michelson AD. Antithrombotic Therapy in Children: The Seventh ACCP Con- 
ference on Antithrombotic and Thrombolytic Therapy. Chest 126:645S-687S, 2004.

79. Paediatric Stroke Working Group. Stroke in Childhood: Clinical Guidelines for Diagnosis, Management and Rehabilitation. Available at: http://www.rcplondon.ac.uk/pubs/books/childstroke/, accessed July 12, 2005.

80. deVeber G. In pursuit of evidence-based treatments for paediatric stroke: the UK and Chest guidelines. Lancet Neurol 4:432-436, 2005.

81. Gruber A, Nasel C, Lang W, Kitzmuller E, Bavinzski G, Czech T. Intra-arterial thrombolysis for the treatment of perioperative childhood cardioembolic stroke. Neurology 54:1684-1686, 2000.

82. Carlson MD, Leber S, Deveikis J, Silverstein FS. Successful use of rt-PA in pediatric stroke. Neurology 57:157-158, 2001.

83. Noser EA, Felberg RA, Alexandrov AV. Thrombolytic therapy in an adolescent ischemic stroke. J Child Neurol 16:286-288, 2001.

84. Kirton A, Wong JH, Mah J, Ross BC, Kennedy J, Bell K et al. Successful endovascular therapy for acute basilar thrombosis in an adolescent. Pediatrics 112:e248-e251, 2003.

85. Golomb MR, Rafay M, Armstrong D, Massicotte P, Curtis R, Hune $S$ et al. Intra-arterial tissue plasminogen activator for thrombosis complicating cerebral angiography in a 17 -year-old girl. $J$ Child Neurol 18:420-423, 2003.

86. NINDS TPA, The National Institute of Neurological Disorders and Stroke rt-PA Stroke Study Group. Tissue plasminogen activator for acute ischemic stroke. N Engl J Med 333:1580-1587, 1995.

87. Meschia JF, Miller DA, Brott TG. Thrombolytic treatment of acute ischemic stroke. Mayo Clin Proc 77:542-551, 2002.

88. Hill MD, Buchan AM. Thrombolysis for acute ischemic stroke: results of the Canadian Alteplase for Stroke Effectiveness Study. CMAJ 172:1307-1312, 2005.

89. Monagle P, Michelson AD, Bovill E, Andrew M. Antithrombotic therapy in children. Chest 119:344S-370S, 2001.

90. Cognard C, Weill A, Lindgren S, Piotin M, Castaings L, Moret J. Basilar artery occlusion in a child: "clot angioplasty" followed by thrombolysis. Childs Nerv Syst 16:496-500, 2000.

91. Andrew M, Vegh P, Johnston M, Bowker J, Ofosu F, Mitchell L. Maturation of the hemostatic system during childhood. Blood 80:1998-2005, 1992.

92. Burak CR, Bowen MD, Barron TF. The use of enoxaparin in children with acute, nonhemorrhagic ischemic stroke. Pediatr Neurol 29:295-298, 2003.

93. Dix D, Andrew M, Marzinotto V, Charpentier K, Bridge S, Monagle $\mathrm{P}$ et al. The use of low molecular weight heparin in pediatric patients: a prospective cohort study. J Pediatr 136:439445,2000

94. Strater R, Kurnik K, Heller C, Schobess R, Luigs P, NowakGoettl U. Aspirin versus low-dose low-molecular-weight heparin: antithrombotic therapy in pediatric ischemic stroke patients: a prospective follow-up study. Stroke 32:2554-2558, 2001.

95. Hirsh J, Warkentin TE, Raschke R, Granger C, Ohman EM, Dalen JE. Heparin and low-molecular-weight heparin: mechanisms of action, pharmacokinetics, dosing considerations, monitoring, efficacy, and safety. Chest 114:489S-510S, 1998.

96. Andrew M, Marzinotto V, Massicotte P, Blanchette V, Ginsberg J, Brill-Edwards $P$ et al. Heparin therapy in pediatric patients: a prospective cohort study. Pediatr Res 35:78-83, 1994.

97. Newall F, Barnes C, Ignjatovic V, Monagle P. Heparin-induced thrombocytopenia in children. J Paediatr Child Health 39:289292, 2003.

98. Massicotte P, Adams M, Marzinotto V, Brooker LA, Andrew M. Low-molecular-weight heparin in pediatric patients with thrombotic disease: a dose finding study. J Pediatr 128:313-318, 1996.

99. Maiti B, Chakrabarti I. Study in cerebral venous thrombosis with specific reference to efficacy of heparin. J Neurol Sci 150:S1471997.

100. Stam J, de Bruijn S, deVeber G. Anticoagulation for cerebral sinus thrombosis. Stroke 34:1054-1055, 2003.

101. Preter M, Tzourio C, Amen A, Bousser MG. Long term prognosis in cerebral venous thrombosis: Followup of 77 patients. Stroke 27:243-246, 1996.
102. deVeber G, Chan A, Monagle P, Marzinotto V, Armstrong D, Massicotte $\mathrm{P}$ et al. Anticoagulation therapy in pediatric patients with sinovenous thrombosis: a cohort study. Arch Neurol 55: 1533-1537, 1998.

103. Ciccone A, Canhao P, Falcao F, Ferro JM, Sterzi R. Thrombolysis for cerebral vein and dural sinus thrombosis. Cochrane Database Syst RevCD003693- 2004.

104. Griesemer DA, Theodorou AA, Berg RA, Spera TD. Local fibrinolysis in cerebral venous thrombosis. Pediatr Neurol 10:78-80, 1994.

105. Wong VK, LeMesurier J, Franceschini R, Heikali M, Hanson R. Cerebral venous thrombosis as a cause of neonatal seizures. Pe diatr Neurol 3:235-237, 1987.

106. Hutchison JS, Ichord R, Guerguerian AM, deVeber G. Cerebrovascular disorders. Semin Pediatr Neurol 11:139-146, 2004.

107. Becker K. Intensive care unit management of the stroke patient. Neurol Clin 18:439-454, 2000.

108. Yager JY, Thornhill JA. The effect of age on susceptibility to hypoxic-ischemic brain damage. Neurosci Biobehav Rev 21:167174, 1997.

109. Baird TA, Parsons MW, Phanh T, Butcher KS, Desmond PM, Tress BM et al. Persistent poststroke hyperglycemia is independently associated with infarct expansion and worse clinical outcome. Stroke 34:2208-2214, 2003.

110. Volpe JJ. Perinatal brain injury: from pathogenesis to neuroprotection. Ment Retard Dev Disabil Res Rev 7:56-64, 2001.

111. Wirrell EC, Armstrong EA, Osman LD, Yager JY. Prolonged seizures exacerbate perinatal hypoxic-ischemic brain damage. Pediatr Res 50:445-454, 2001.

112. Sugawara T, Fujimura M, Noshita N, Kim GW, Saito A, Hayashi $\mathrm{T}$ et al. Neuronal death/survival signaling pathways in cerebral ischemia. NeuroRx 1:17-25, 2004.

113. Cho DY, Chen TC, Lee HC. Ultra-early decompressive craniectomy for malignant middle cerebral artery infarction. Surg Neurol 60:227-232, 2003.

114. Gupta R, Connolly ES, Mayer S, Elkind MS. Hemicraniectomy for massive middle cerebral artery territory infarction: a systematic review. Stroke 35:539-543, 2004.

115. Kirkham F, deVeber G,.Chan A,. Strater R. Ganesan V, Prengler M. Nowak-Gottl U. Recurrent arterial ischemic stroke: The role of prothrombotic disorders. Ann Neurol 54(Supp 7):S110, 2003.

116. deVeber G, Monagle P, Chan A, MacGregor D, Curtis R, Lee S et al. Prothrombotic disorders in infants and children with cerebral thromboembolism. Arch Neurol 55:1539-1543, 1998.

117. Lanthier S, Kirkham FJ, Mitchell LG, Laxer RM, Atenafu E, Male $\mathrm{C}$ et al. Increased anticardiolipin antibody IgG titers do not predict recurrent stroke or TIA in children. Neurology 62:194200, 2004.

118. Kurnik K, Kosch A, Strater R, Schobess R, Heller C, NowakGottl U. Recurrent thromboembolism in infants and children suffering from symptomatic neonatal arterial stroke: a prospective follow-up study. Stroke 34:2887-2892, 2003.

119. Sandercock PA, van den Belt AG, Lindley RI, Slattery J. Antithrombotic therapy in acute ischaemic stroke: an overview of the completed randomised trials [see comments]. I Neurol Neurosurg Psychiatry 56:17-25, 1993.

120. Albers GW, Amarenco P, Easton JD, Sacco RL, Teal P. Antithrombotic and thrombolytic therapy for ischemic stroke. Chest 119:300S-320S, 2001.

121. Mohr JP, Thompson JL, Lazar RM, Levin B, Sacco RL, Furie KL et al. A comparison of warfarin and aspirin for the prevention of recurrent ischemic stroke. $N$ Engl J Med 345:1444-1451, 2001.

122. Nowak-Goettl U, Straeter R, Sebire G, Kirkham F. Antithrombotic drug treatment of pediatric patients with ischemic stroke. Paediatr Drugs 5:167-175, 2003.

123. Domi T, Thomas S, Rand M, Chan AK, Lanthier S, Clarke D, deVeber G. A study of platelet response to aspirin in children with arterial ischemic stroke utilizing the PFA 100 analyzer. Stroke 35(1):P284, 2005.

124. Hune S, Rafay MF, Domi T, Allen A, Chan C, deVeber G. Plavix (Clopidogrel) in Pediatric Stroke: Monitoring of side effects and patient education strategies. Stroke 35:284- 2004. 
125. Golomb MR, Hune S, MacGregor DL, deVeber GA. Alternative therapy use by Chinese-Canadian children with stroke and cerebrovascular disease. J Child Neurol 18:714-717, 2003.

126. Wolters HJ, ten Cate H, Thomas LL, Brandjes DP, van der EA, van der HY et al. Low-intensity oral anticoagulation in sickle-cell disease reverses the prethrombotic state: promises for treatment? Br J Haematol 90:715-717, 1995.

127. Sumoza A, de Bisotti R, Sumoza D, Fairbanks V. Hydroxyurea (HU) for prevention of recurrent stroke in sickle cell anemia (SCA). Am J Hematol 71:161-165, 2002.

128. Kirkham FJ, Hewes DK, Prengler M, Wade A, Lane R, Evans JP. Nocturnal hypoxaemia and central-nervous-system events in sickle-cell disease. Lancet 357:1656-1659, 2001.

129. Mikulis DJ, Krolczyk G, Desal H, Logan W, deVeber G, Dirks P et al. Preoperative and postoperative mapping of cerebrovascular reactivity in moyamoya disease by using blood oxygen level-dependent magnetic resonance imaging. J Neurosurg 103: 347-355, 2005.

130. Fung LW, Thompson D, Ganesan V. Revascularisation surgery for paediatric moyamoya: a review of the literature. Childs Nerv Syst 21:358-364, 2005.

131. Kim SK, Seol HJ, Cho BK, Hwang YS, Lee DS, Wang KC. Moyamoya disease among young patients: its aggressive clinical course and the role of active surgical treatment. Neurosurgery 54:840-844, 2004.

132. Taub E, Ramey SL, DeLuca S, Echols K. Efficacy of constraint-induced movement therapy for children with cerebral palsy with asymmetric motor impairment. Pediatrics 113:305312, 2004. 